\title{
Integral Framework as a Systemic Foundation for Coaching
}

\author{
JP Jakonen \\ Pori Area, Finland
}

\author{
Matti Kamppinen \\ Turku, Finland
}

\begin{abstract}
Coaching as a combination of cognitive and behavioral techniques can be founded upon different knowledge bases, or frameworks. Like positive psychology or consulting psychology, coaching utilizes theories from developmental psychologies and other knowledge bases concerning human transformation. We argue that systemic coaching is best facilitated by the integral framework that acknowledges the diversity and multi-faceted nature of human existence. Following Ken Wilber and Robert Kegan, we reconstruct and discuss integral coaching (as developed by Joanne Hunt and Laura Divine) as a systemic coaching approach that is based on integral framework. We conclude that the integral framework is needed not only for truly systemic coaching, but also for the construction of wisdom cultures that acknowledge the big picture, or systemic relationships beyond one's immediate surroundings
\end{abstract}

Keywords: integral framework, integral coaching, four quadrants model, $A Q A L$ model, knowledge base of coaching, developmental psychology, adult thinking, positive psychology, consulting psychology, wisdom culture.

\section{Introduction}

Enabling transformations in people, cultures and organizations is hard, as anyone who has tried it can attest. Systems have a tendency towards a state known as homeostasis, which is commonly felt as a resistance or even immunity to change (Kegan \& Lahey, 2001; Kegan \& Lahey, 2009). This inherent difficulty has led the coaching field to search for more effective, more inclusive and more systemic approaches to facilitating change (see, for example, Whittington, 2016). 
This article discusses how one of those approaches, namely integral coaching is applicable to the problems and process of systemic coaching ${ }^{1}$. In particular we argue, following Hunt and Divine (2009), that we need to go towards an integral approach in coaching in order to differentiate the factors that compose the ontological territory we face as coaches. Having done that, we can more effectively integrate those systemic factors in using appropriate coaching interventions coming from many different perspectives in a contextually effective and coherent way (Divine, 2009a; Watkins, 2014).

Integral coaching uses as its theoretical basis the subject-object theory of Robert Kegan $(1982,1994)$ and the integral theory of Ken Wilber $(1995,2000$, 2016). The aim of this article is to introduce the reader to the integral framework and discuss its relevance to the development of systemic coaching (Jakonen \& Kamppinen, 2015; Cacioppe \& Edwards, 2005). This endeavor is framed within an examination of Ken Wilber's integral model and its basic framework. ${ }^{2}$ We further argue that the general model of human being behind coaching technologies - the lenses through which coaches see their clients - is the key to how transformation is facilitated. We will conclude with an appraisal of how integral theory is implemented in integral coaching and propose that the concept of wisdom culture is an optimal context for integral development in coaching individuals and organizations.

\section{Voluntary cognitive technologies in facilitating transformations}

Transformation of thinking and doing occurs naturally, but it can also be induced, or facilitated, usually by means of voluntary cognitive and behavioral technologies like coaching and consulting. Following the systems philosophy of Mario Bunge, we understand technology as the design of things or processes of possible practical value to some individuals or groups with the help of knowledge gained in basic or applied research (Bunge 2001,345). The things and processes in question can be physical, biological, social or psychological. In fact, the profession of coaching psychology is one of the major fields of applied adult psychology, as evidenced not only in the number of coaching professionals, but more importantly, in the number of coaching psychology journals and handbooks (see Palmer \& Whybrow, 2014). Leadership

\footnotetext{
${ }^{1}$ Integral Coaching as a technique is a registered trademark of Integral Coaching Canada. Here we describe, analyze and contextualize the general idea of integral coaching as an application of integral theory in coaching. For an assessment of integral coaching, see Frost (2009).

${ }^{2}$ We will use the terms framework, model, theory and approach when referring to integral thinking. As a general theory it belongs to the foundational studies of more particular psychological theories (cf. Bunge, 1983).
} 
development as well as organizational learning provide additional examples (Senge, 1990; Laloux, 2014).

Coaching relates to developmental psychology as technology relates to basic science: the knowledge base is used in order to bring about a planned change in the world. In the case of coaching, the knowledge base is used for the enhancement of life experience, work performance and well-being for individuals, groups and organizations (Grant, 2006).

The varieties of coaching psychology stem from their background models of human being - how human beings are understood - and their related theories of learning and transformation: behavioral psychology provides building blocks for different kinds of coaching than cognitive psychology, and developmental psychology provides yet another set of tools for applied coaching. Positive psychology (Sinnott, 2013; Linley \& Joseph, 2004; Linley \& Harrington, 2005) has been traditionally best suited for the needs of coaching. We propose to extend positive psychology and argue that an integral or systemic framework that combines elements from different knowledge bases, including various psychological models, would provide conditions for an optimal coaching technology, since it would take into account the different aspects of human transformation and adult thinking. Parallel development has taken place in integrative psychotherapy that has combined parts of various fields of psychology in its approach (Erskine \& Moursund, 2018).

It should be noticed, though, that the criteria of goodness for background theories and technological models are different. Theories, especially scientific theories, aim at capturing the dynamics of reality, and thus at generating epistemic utilities like true descriptions, sound explanations and accurate predictions of the future. Technological models, on the other hand, aim at having practical utilities, that is, they succeed in bringing about change in the world (Bunge, 1985). Therapies and coaching techniques that help their patients or clients but have vague or no background theories abound in the wellbeing industry - a coaching technique may work even though its background theory is obscure or outdated in the light of our current scientific understanding of the world. On the other hand, analyzing a coaching technology and its background theory will provide a good case of how human development is understood in theory and practice. 


\section{The integral framework}

The basic premise of Ken Wilber's integral framework is simple and seen in many different strands of scientific inquiry, especially in systems thinking (Senge, 1990; Hämäläinen \& Saarinen, 2008): nothing is so simple that it can be thoroughly understood or explained (away) with only one perspective or approach. The reduction of a multifaceted reality into only one of its constituents and the scientific orientations that corresponds to that particular corner of the universe, be it physics, chemistry, neuroscience, phenomenology, hermeneutics, psychoanalysis, cognitive psychology or postmodern sociology is, according to the integral approach, intellectually true but partial. It is true in the sense that physics, psychology, cultural studies and systems theory all cover the same terrain - the ontology of the universe. In covering this vast terrain, they are able to, and they also should, use their particular intellectual and academic skill set to make sense of this one perspective as thoroughly as they can. This thorough investigation, however, does not amount to making any ontologically reductive claims, be they physical, neural or mental in nature. In this sense it is partial, as all of the known fields of scientific research cover only certain, particular dimensions or corners of reality.

One of the main purposes of the integral approach is to systemize and synthesize this knowledge and show how these parts interact in the biggest possible picture (Wilber, 1995). Integral model can be seen, then, as a metamodel or a meta-theory of different, and often competing theories in several fields of scientific (and also spiritual and other knowledge-seeking) inquiries. It is comparable to systems thinking even though it aims at supplementing the objective systemic orientation with the hermeneutics of subjective perspectives (Kamppinen \& Jakonen, 2015). The basic tenets of this biggest possible picture, and its relevance to the process of adult development, are examined next.

\subsection{Horizontal and vertical components of the integral model}

The integral (or AQAL, standing for All Quadrants, All Levels, All Lines, All States and All Types) model has two main components: horizontal and vertical (Jakonen \& Kamppinen, 2017). The horizontal component refers to the perspectives available at any time in acquiring knowledge. The vertical component refers to the levels present in the evolution of consciousness. The horizontal component can be exemplified as a four-quadrant table. 


\begin{tabular}{|c|c|}
\hline $\begin{array}{l}\text { INTERIOR-INDIVIDUAL OF “I”" } \\
\text { (UPPER LEFT SELF) }\end{array}$ & $\begin{array}{l}\text { EXTERIOR-INDIVIDUAL OF “IT" } \\
\text { (UPPER RIGHT STRUCTURE) }\end{array}$ \\
\hline $\begin{array}{l}\text { Phenomenology (psychoanalysis, } \\
\text { dream interpretation, meditative } \\
\text { disciplines) } \\
\text { - Parts of developmental } \\
\text { psychology } \\
\text { - Introspection } \\
\text { - Language of "I" (from inside a } \\
\text { person) }\end{array}$ & $\begin{array}{l}\text { - Natural sciences (biology, } \\
\text { behaviourism, chemistry, etc) } \\
\text { - Empirical observation } \\
\text { - Language of "It" (from outside } \\
\text { a person) }\end{array}$ \\
\hline 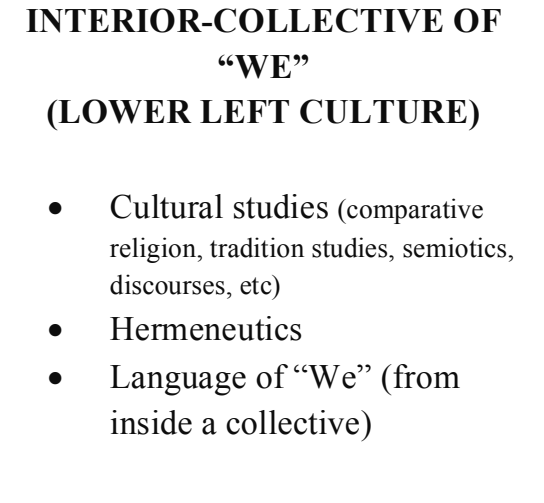 & $\begin{array}{c}\text { EXTERIOR-COLLECTIVE OF } \\
\text { "ITS" } \\
\text { (LOWER RIGHT SYSTEM) } \\
\text { - } \quad \begin{array}{l}\text { Systems sciences (engineering, } \\
\text { ecology, syntax, etc) }\end{array} \\
\text { - Information systems } \\
\text { - Collective empirical } \\
\text { observation } \\
\text { - Language of "Its" (from } \\
\text { outside a collective }\end{array}$ \\
\hline
\end{tabular}

Figure 1: The Four Quadrants of the Integral AQAL Model (adapted from Wilber, 1995)

On the left-hand side we have the inner, subjective views of the world. On the right-hand side are the exterior, objective views of the world. Both views have a singular and a plural - or an individual and a collective component. Thus, the world can be seen from four different dimensions. Furthermore, AQAL theory posits that reality is usually approached from only one or two of these dimensions, but rarely from all four. This results in what is called quadrant absolutism, that is, reducing the many-faceted reality, knowledge and being-in-the-world to only one of its perspectives. This can be seen as, for example, in trying to explain consciousness as only a biological phenomenon (upper right reduction), or only as a contextual phenomenon (lower left or lower right reduction), and so on. Consciousness and its 
development is, rather, a tetra-emergent phenomenon, that has correlates in each of the four horizontal dimensions ${ }^{3}$.

All four horizontal quadrants evolve. This evolution spans various vertical levels: both structure and self, as well as cultures and systems go through stages of growth. The most obvious example is human consciousness: we go from early concepts to formal logic to systemic thinking and beyond. The AQAL model is based on a study of several different developmental theories in several different developmental lines such as sociocultural, empathy, morals, spirituality, socioemotional, self-outlook, ego development, needs, and many more, from a variety of developmental theorists such as Piaget (1977), Kohlberg (1990), Loevinger (1987), Gebser (1985), Fowler (1981), Commons $\&$ Richards (1984) and Kegan $(1982 ; 1994)^{4}$. These levels are seen in the integral theory to form a rainbow-like spectrum described as altitude of consciousness. Along this altitude are several separate lines of development that traverse through the same general levels, ranging from pre-egoic to egoic to post-egoic, or egocentric to ethnocentric to worldcentric, or pre-rational to rational to trans-rational (Wilber, 1995; 2006; 2017a). These two dimensions the horizontal perspectives that consciousness can take at any moment, and the vertical levels that consciousness can evolve through - are the two cornerstones of Ken Wilber's integral theory.

Beyond these three components - perspectives, levels and lines - the AQAL model differentiates as central constituents of human consciousness the variable states of consciousness and types of consciousness or personality types. Typology can be used within any viable and valid framework, such as MyersBriggs, DiSC profile or the Enneagram, to indicate how and where the personality is directed in terms of energy and attention (Briggs Myers, 1995; Rosenberg \& Silvert, 2015; Riso \& Hudson, 1999). States can be categorized, following various wisdom traditions, as gross waking state, subtle dream state, causal absorption state and nondual oneness state (Wilber, 2016). These five building blocks (quadrants, levels, lines, states and types) are the keystones of the integral model. Next, we will proceed to look at how it applies to the problems and process of coaching.

\footnotetext{
3 The four quadrant model is further complexified in Wilber (2006) into eight methodological zones, where each quadrant can be accessed from the inside and from the outside, placing, for example, developmental psychology into "Zone 2" of Interior-Subjective quadrant, and phenomenological studies into "Zone 1" of the same quadrant.

4 For an exhaustive comparison of different developmental models and their respective stages in several lines of development, see Wilber 2000, pp. 197-217.
} 


\section{Four perspectives into change in integral coaching}

Coaching is a profession concerned with the issues of fostering, sustaining and nurturing change in adult human beings. Despite their unifying core purpose coaching schools have different underlying belief structures and theories around change: what makes it happen, what are the main factors in sustaining it, and what does it actually mean to change. The integral framework provides tools for contextualizing the four different orientations or theories on how change and transformation is thought to occur in various schools of coaching (Hunt, 2009a, 2009b). That is, the four quadrant model can be used in contextualizing these different orientations and beliefs (Bachkirova et al., 2010; Hunt, 2009b; Jakonen \& Kamppinen, 2015).

Figure 2: Common belief structures for change (Hunt, 2009a, 3; used with permission from Integral Coaching Canada)

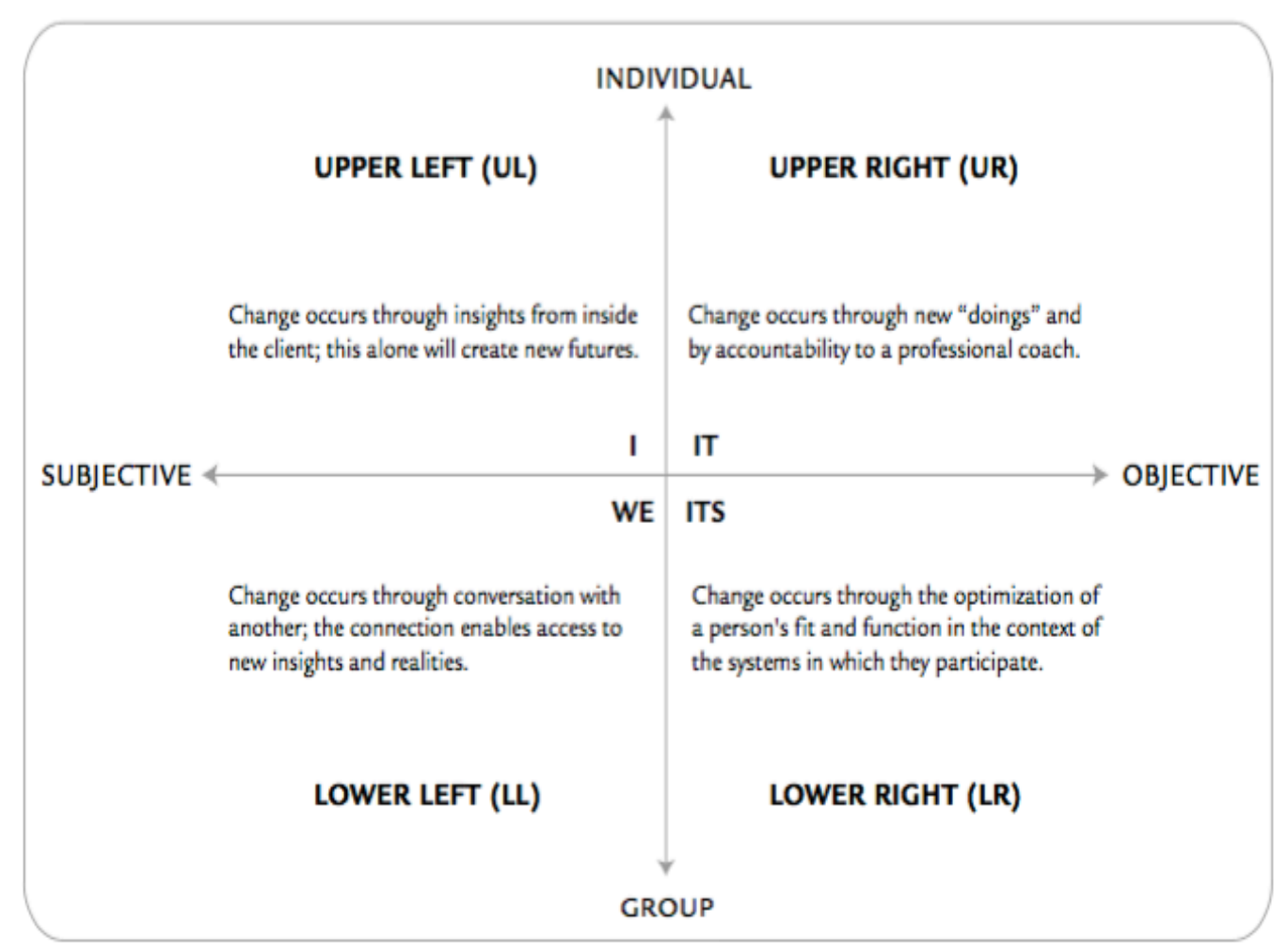

Coaching from the upper-left perspective means helping the coaching client in discovering new realities, new insights and new possibilities from within themselves. Change is thought to occur by disclosing or questioning 
assumptions or perceptions that access inner wisdom that is somehow inherent, as if the answers to complex problems the client faces are already formed, and they need to emerge and be mined as if they were diamonds to be discovered. UL approach to change has a lot to do with the psychoanalytic tradition in the sense that it is based on helping the client become more truthful regarding their inner world, as well as giving more correct interpretations to both their unconscious and emergent inner reality (Wilber 1995; Scharmer 2009). Coaching from the UL thus requires the client to learn to see, hear and trust their inner wisdom, while also giving it a new voice (Hunt, 2009a).

Coaching from the upper-right perspective means helping the coaching client in taking action. Orienting from a "doing" standpoint, UR orientation helps the coachee in taking deliberate steps in a new direction - it is an objective correlation to the UL orientation, where emphasis is given in thinking in a new and a different way - and setting measurable goals. According to UR coaching schools, change happens as we physically do different things: speak, act and behave as if the new me is already in place. This behavioristic orientation is often seen in many orientations of executive and business coaching, possibly due to its supposed effectiveness in developing new measurable skills, achieving new results and "getting things done" (Hunt, 2009a; Allen, 2001).

Coaching from the lower left perspective means helping the coaching client in having powerful conversations and sharing meaning in a cultural setting that provides new insights that would not be possible through individual intent alone. This is often referred to as "sparring" with a trusted partner, shooting out thoughts and plans as if testing the waters for them to sink or float. This approach, grounded in a hermeneutical tradition, holds the coach as a collaborative thinking partner who acts as a springboard and a catalyst for the client's new perspectives to come about. This inner-subjective view is close to the upper-left schools in maintaining that change happens as a result of a new way of thinking about things. Here, however, the relationship between the coach and the client, and the factors that play a part in it, like deep listening and presence as separate coaching skills, are given special attention. LL approach is particularly useful when applied to team coaching in relation to, for example, having a shared understanding of team rules, team commitments or team roles (Hawkins, 2017; Hunt, 2009a).

Coaching from the lower right perspective means helping the client in optimizing the fit and function of the client in their systemic context. It might mean having their roles examined in relation to the coaching topic: making 
changes in their professional or personal environment. It might mean a new overall plan or a strategy in order to make the client relate in a new way to the big picture they are a part of, be it work, family, partnering, parenting or other different responsibilities modern life makes us juggle with, often with less than desirable results (Kegan, 1994). Echoes from this systemic-role-optimizing coaching orientation can be seen, for example, in the popular work of Stephen R. Covey (1988), where having a time and a place for various intersecting roles in life is one of the keys to effectiveness, although Covey's work could be situated in the UR orientation as well. Lower right orientation also emphasizes an understanding of the structure of the context (company, family, life in its totality) the client is a part of. In business coaching, lower-right perspective takes into account things such as team structure, operating principles, areas of responsibility, expectations, and other such objective pieces of the whole that are systematically linked.

The basic premise of the integral coaching is that all of the quadrants are needed for change to effectively happen, integrate and sustain over time (Hunt, 2009a). UL perspective ensures that thinking and inner subjective insights ("You change when you want to change and start thinking in new ways") are in place. UR perspective helps in taking observable action steps in the new direction ("You change by doing new things"). LL perspective makes sure that the change is not only subjective, but measured against a human connection and interaction, where professional coaching conversations ("I really think your interactions show a real change in your way of being, keep it up") function as guideposts showing if the perceived change is actually happening at all or not. LR perspective helps in making it all come together by seeing how the client is effecting and being effected by many environmental, systemic and contextual forces ("You might benefit from simplifying the structures in the organizations you belong to."). The client is always a part of a family, an organization, a team, and many more self/other relations that participate in the mutual give and take of the coachee's energy and time in relation to their coaching topic. With only one or two of these perspectives, the adult development process known as coaching - or, as far as it is transferrable into clinical work, psychology, psychotherapy and counseling - is fostering change in a true but partial fashion (Hunt, 2009a; Marquis, 2008; Wilber, 20005). New insights (UL) do not

\footnotetext{
${ }^{5}$ See for example Wilber (2000, pp. 288): "[E]ven though psychology focuses on the UpperLeft quadrant, all four quadrants are required for psychological understanding, since all four quadrants determine the state of consciousness of the individual", or Ingersoll (in Marquis 2008, pp. ix): "Mental health professionals are overly specialized, and such specialization,
} 
necessarily translate into action; new actions (UR) are not necessarily translated into new ways of seeing oneself; new systemic changes (LR) do not necessarily turn into shared cultural values; and new and even powerful conversations (LL) do not necessarily lead into personal empowerment, but can, in the worst case, lead into a client-coach-dependency relationship that benefits the financial situation of the coach more than the embodied change of the coachee.

Besides contextualizing the different belief structures for change, the four quadrant model can be used in adult development as a (i) competency assessment, (ii) type structure, and (iii) worldview translation tool. The first is a way of "looking at" a person (the coaching client), and the other two are ways of "looking as" a person (Divine, 2009a): to assess competencies is to observe; to understand how the client sees the world by seeing his or her type structure ("Native Perspective") and how the world appears to him or her because of that structure is to walk a mile in his or her shoes, that is, to interpret and empathize.

\subsection{Process of change in integral coaching}

Integral coaching proceeds through a four-stage process of change with distinct transformational conversations. The purpose of these conversations is, firstly, to help the client to see their current approach of thinking and action (aka "Current Way of Being") towards the thing they wish to change (aka "The Coaching Topic"). As the subject of the current stage starts to become an object (Kegan, 1982), a new approach (aka "New Way of Being") is being introduced with a few key developmental skills (aka "Developmental Objectives") that are pertinent to the topic and lacking in developmental altitude in the current AQAL constellation of the client. These skills are systematically developed through practices between the cycles of development conversations. In the completion phase - after some 3 to 12 months of developmental work - the new skills have sufficiently helped to build the muscles needed for the client to internalize or embody the change from their Current Way into a New Way of being and relating towards the topic (Hunt, 2009a).

while offering useful distinctions about the psychological trees, lacks a vision of the forest of the psyche." 
Figure 3: One transcend and development cycle (Hunt 2009a, 16; used with permission from Integral Coaching Canada)

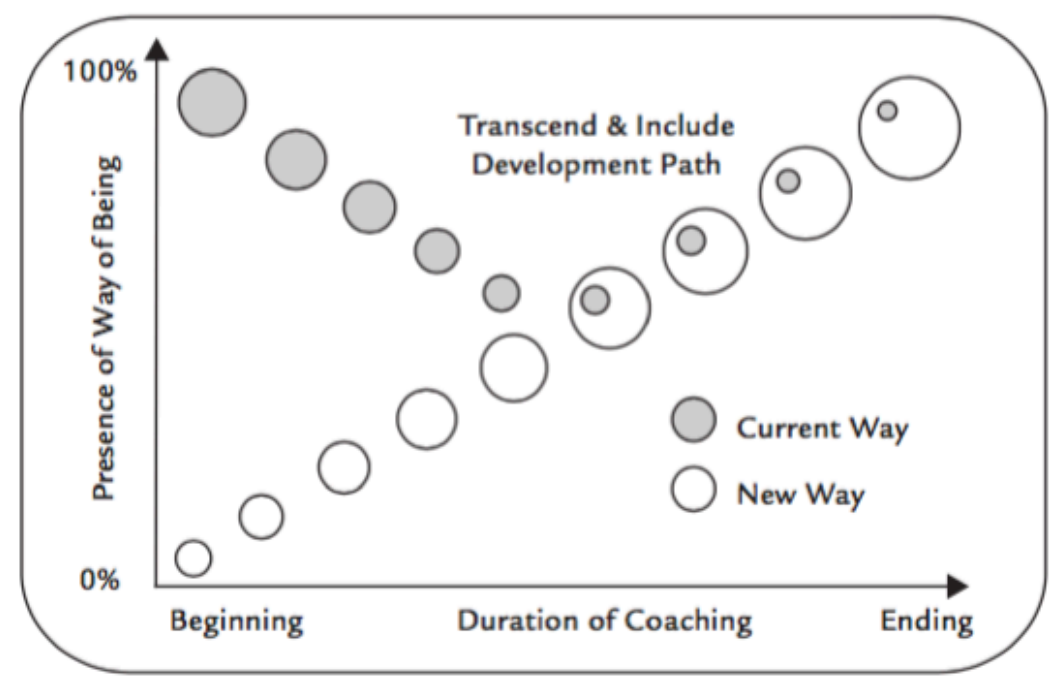

\subsection{Differentiating horizontal and vertical growth}

The development facilitated by integral coaching has two dimensions to it: horizontal and vertical. The first is more common, with the latter being a byproduct of healthy horizontal growth. As the process begins, the current way of being is the subject through which the world is seen. As a subject, it is not yet visible to the client, but an unconscious driver in their life. As the process continues, the current way starts to become an object. As an object, the client is now able to be in relation to it and dis-identify with it. Building new developmental capacities then helps the new way of being in becoming a new object with which to identify. As the new way becomes embodied over time, and becomes the new subject, the former (current) way is transcended but included in the new way of being. Our former selves and former subjectivities never disappear but rather become parts of a larger whole we grow into. 
Figure 4: Repeating cycles of transcend and include development (Hunt, 2009a, 16; used with permission from Integral Coaching Canada)

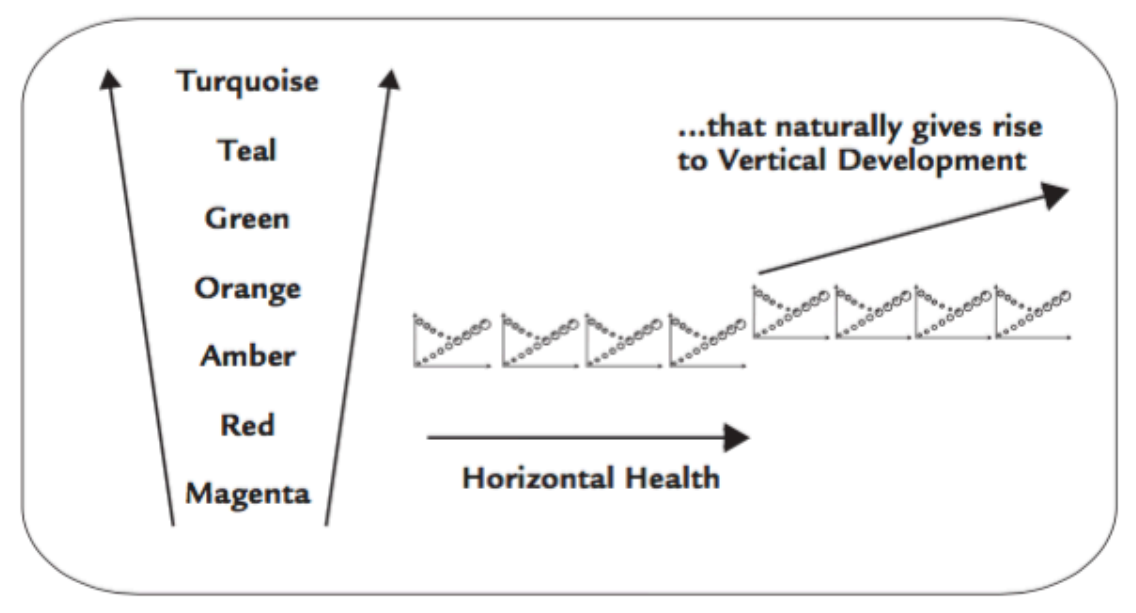

This process usually facilitates and is initiated from the motivations of translational growth for the client: how can I be a more effective/better/skillful leader/parent/spouse from within my current altitude? How can I translate this language I don't understand ("To be a more direct communicator", for example) into something I can handle? We seek cures for the pain; not a new level from which pains are approached. But, as enough horizontal growth has happened; as enough space has been made by removing stress from our current altitude; as we ease our way into being more and more at home in the universe, evolution of consciousness seems to call forth in us a transformation into the level surpassing our current meaning-making model. This vertical growth to another level (i.e. from Orange to Green) moves from the wobbly stage (getting to know the contours of the altitude) to solid (being identified with an altitude) to disintegrating (transcending and including to a new altitude). Vertical transformation is not the primary focus in integral coaching, but it can - and sometimes does - happen as the client has made enough progress in the subjectobject process of human development (Divine, 2009a, 2009b; Hunt, 2009a, 2009b; Kegan, 1982).

\section{Conclusion: Towards an evolutionary wisdom culture in coaching}

Scientific disciplines and technological application are in mutual interaction: knowledge bases formed in basic science are used in applied science and technology, and practical applications feed new questions and 
challenges for basic research, and breakthroughs in basic research give birth to new technologies. In natural science, there is seldom need to expand the knowledge base with culturally specific models of reality for the simple reason that there is no Canadian physics apart from European physics. It is all just physics. But in the area of psychology and especially in human development, the knowledge base can be expanded with culturally specific models of human mind and action, and related models of reality. The human being is a process, under construction, and therefore different knowledge bases bring forth different potentialities in being human. This is especially clearly seen in coaching practices, since they implement models of thinking and doing and have been traditionally based on various kinds of psychological theories, including coaching psychology proper and positive psychology. Our example, integral coaching, is based on the integral framework that aims at bringing together different knowledge bases about human being and development, including transpersonal and cross-cultural psychology.

The integral framework is needed not only in our projects of understanding and creating knowledge, but also in our attempts to create better organizations, better leadership and better societies. We need an orienting model and a theory of human consciousness in order to take into account all the crucial factors that come into play when different types, states, lines, levels and perspectives interact.

Futurist and foresight expert Richard Slaughter (2012) has introduced the notion of wisdom culture. This culture is pervaded by systems-thinking (or spirituality) in the sense that in it there is a sense of belonging to a wider pattern, and seeing the world as a systemic whole, where the flatland ${ }^{6}$ of onedimensional living is transcended.

If our sense of belonging to a wider pattern extends from our individual ego to our group, our nation, our tribe, we create an ethnocentric wisdom culture - a significant transformation compared with an egocentric orientation. If this sense extends to all nations, all peoples, all races, all colours, all creeds, we create a world-centric wisdom culture. If our sense of belonging to a wider pattern extends to all sentient beings, all perspectives, all levels, we create a cosmo-centric, i.e. integral wisdom culture. And if this sense extends to evolution itself, we might have created an evolution-centric or post-integral wisdom culture. This process of transcending and including an altitude of

${ }^{6}$ Flatland is a term Wilber uses, after the novelist Edwin A. Abbott, to describe the worldview where only material realities (the objective right-hand quadrants) are thought to be real. 
development is at the heart of creating conscious wisdom cultures both individually and as an organization. Integral coaching, then, can be seen as an organizational vehicle by which we create these systemic wisdom cultures starting from grass-root level of individual understanding.

\section{References}

Allen, D. (2001). Getting things done: The art of stress-free productivity. New York: Penguin.

Beck, D \& Cowan, C. (1996). Spiral dynamics. New York: Wiley.

Bachkirova, T., Cox, E. \& Clutterbuck, D. (2010). 'Introduction' in T. Bachkirova, E. Cox and D.A. Clutterbuck (Eds.), The complete handbook of coaching (pp. 1-20). London, SAGE Publications.

Briggs Myers, I. \& Myers, P. (1995). Gifts differing: Understanding personality types. Mountain View, Davies-Black Publishing.

Bunge, M. (1983). Epistemology and methodology part I: Exploring the world. Dordrecht: Reidel Publishing.

Bunge, M. (1985). Philosophy of science and technology Part II: Life science, social science and technology. Dordrecht: Reidel Publishing.

Bunge, M. (2001). The nature of science and technology. In M. Mahner (Ed.), Scientific realism: Selected essays of Mario Bunge (pp. 345-351). Buffalo: Prometheus Books.

Cacioppe, R. \& Edwards, M. (2005). Seeking the Holy Grail of organisational development: A synthesis of integral theory, spiral dynamics, corporate transformation and action inquiry. Leadership \& Organization Development Journal, 26(1), 86-105.

Commons, M.L. \& Richards, F.A. (1984). Applying the general stage model. In M.L. Commons, F.A. Richards, \& C. Armon (Eds.), Beyond formal operations: Vol. 1. Late adolescent and adult cognitive development, (pp 141-157). New York: Praeger.

Covey, S. (1988). The 7 habits of highly effective people. New York: Free Press.

Dalal, A.S. (Ed.). (2000). A greater psychology: An introduction to the psychological thought of Sri Aurobindo. New York: Tarcher/Putnam.

Divine, L. (2009a). Looking AT and looking AS the client: The quadrants as a type structure lens. Journal of Integral Theory and Practice, 4(1), 2140.

Divine, L. (2009b). A unique view into you: Working with a client's AQAL constellation $^{\mathrm{TM}}$. Journal of Integral Theory and Practice, 4(1), 41-67.

Erskine, G \& Moursund, J. (2018). Integrative psychotherapy in action.

London: Routledge. 
Fowler, J. (1981). Stages of faith: The psychology of human development and the quest for meaning. New York: Harper \& Row.

Frost, L. (2009). Integral perspectives on coaching. An analysis of Integral Coaching Canada across eight zones and five methodologies. Journal of Integral Theory and Practice, 4(1), 94-120.

Gebser, J. (1986). The ever-present origin. Athens: Ohio University Press.

Grant, A.M. (2006). A personal perspective on professional coaching and the development of coaching psychology. International Coaching Psychology Review, 1(1), 12-22.

Hawkins, P. (2017). Leadership team coaching: Developing collective transformational leadership. London: Kogan Page.

Hämäläinen, R. P. \& Saarinen, E. (Eds.). (2008). Systems intelligence: A new lens on human engagement and action. Laboratory for systems analysis: Aalto University.

Hunt, J. (2009a). Transcending and including our current way of being: An introduction to Integral Coaching. Journal of Integral Theory and Practice, 4(1), 1-20.

Hunt, J. (2009b). Transformational conversations: The four conversations of Integral Coaching ${ }^{\circledR}$. Journal of Integral Theory and Practice, 4(1), 6992.

Jakonen, JP. \& Kamppinen, M. (2015). Creating wisdom cultures. Approaching Religion, 5, 15-26.

Jakonen, JP. \& Kamppinen, M. (2017). Kokonaisuuden näkemisen taito: Johdatus integraaliseen ajatteluun (Introduction to integral thinking). Helsinki: Basam Books.

Kamppinen, M \& Jakonen JP (2015). Systems thinking, spirituality and Ken Wilber. Approaching Religion, 5, 3-14.

Kegan, R. (1982). The evolving self. Problem and process in human development. Cambridge: Harvard University Press.

Kegan, R. (1994). In over our heads. The mental demands of modern life. Cambridge: Harvard University Press.

Kegan, R \& Lahey, L. (2001). How the way we talk can change the way we work. New York: Wiley.

Kegan, R. \& Lahey, L. (2009). Immunity to change. Cambridge: Harvard Business Review Press.

Kohlberg, L. (1990). Which postformal levels are stages? In M. Commons et al. (Eds.), Adult Development Volume 2 (pp. 263-268). New York: Praeger.

Laloux, F. (2014). Reinventing organizations. Millis: Nelson Parker Publishing. 
Laloux, F. (2016). Reinventing organizations: An illustrated invitation to join the conversation on next-stage organizations. Millis: Nelson Parker Publishing.

Linley, P.A. \& Harrington, S. (2005). Positive psychology and coaching psychology: perspectives on integration. The Coaching Psychologist, 1, 13-14.

Linley, P.A. \& Joseph, S. (Eds.). (2004). Positive Psychology in Practice. New York: Wiley.

Loevinger, J. (1987). Paradigms of personality. New York: WH Freeman.

Loher, J. \& Schwartz, T. (2003). The power of full engagement: Managing energy, not time, is the key to high performance and personal renewal. New York: Free Press.

Marquis, A. (2008). Integral intake: A guide to comprehensive idiographic assessment in integral psychotherapy. London: Routledge.

Meyerhoff, J. (2010). Bald ambition: A critique of Ken Wilber's theory of everything. California, USA: Iron Curtain Press. Accessed on November $28^{\text {th }}, 2018$ at http://www.integralworld.net/meyerhoff-ba-toc.html

Miller, M. \& Cook-Greuter, S. (1994). Transcendence and mature thought in adulthood. Lanham: Rowman \& Littlefield.

Miller, M \& Cook-Greuter, S. (Eds.). (2000). Creativity, spirituality, and transcendence. New York: Elsevier Science.

Palmer, S \& Whybrow, A. (Eds.). (2014). Handbook of coaching psychology. London: Routledge.

Patterson, K., Grenny, J., McMillan, R., Switzer, A. (2002). Crucial conversations: Tools for talking when stakes are high. New York: McGraw-Hill.

Riso, D. R. \& Hudson, R. (1999). The wisdom of the enneagram: The complete guide to psychological and spiritual growth for the nine personality types. New York: Bantam Books.

Rosenberg, M. \& Silvert, D. (2015). Taking flight!: Master the DISC styles to transform your career, your relationships...your life. New Jersey: FT Press.

Senge, P. (1990). The fifth discipline: The art \& practice of the learning organization. New York: Currency Doubleday.

Scharmer, C.O. (2009). Theory U: Leading from the future as it emerges. San Francisco: Berrett-Koehler.

Sinnott, J., ed. (2013). Positive psychology: Advances in understanding adult motivation. New York, Springer.

Slaughter, R. (2012). To see with fresh eyes. Indooroopilly: Foresight International. 
Visser, F. (2003). Ken Wilber: Thought as passion. Buffalo: SUNY Press. Watkins, A. (2014). Coherence: The secret science of brilliant leadership. London: Kogan Page.

Watkins, A. (2016). 4D leadership. London: Kogan Page.

Whittington, J. (2016). Systemic coaching and constellations: The principles, practices and application for individuals, teams and groups. London: Kogan Page.

Wilber, K. (1995). Sex, ecology, spirituality: The spirit of evolution. Boston: Shambhala.

Wilber, K. (1999). One taste. Boston: Shambhala.

Wilber, K. (2000). Integral psychology: Consciousness, spirit, psychology, therapy. Boston: Shambhala.

Wilber, K. (2006). Integral spirituality: A startling new role for religion in the modern and postmodern world. Boston: Integral Books.

Wilber, K. (2016). Integral meditation: Mindfulness as a way to grow up, wake up, and show up in your life. Boston: Shambhala.

Wilber, K. (2017a). The religion of tomorrow: A vision for the future of the great traditions. Boston: Shambhala.

Wilber, K. (2017b). Trump and a post-truth world. Boulder: Shambhala.

Wilber, K. (2018). Integral Buddhism and the future of spirituality. Boulder: Shambhala. 